\title{
Energy factors for flexible fuel engines and vehicles operating with gasoline-ethanol blends
}

\section{Toshizaemom Noce}

\section{Rafael Rocha da Silva}

\section{Rafael Morais}

Luis Carlos Monteiro

luis.c.monteiro@ig.com.br

\section{Sérgio de Morais Hanriot ${ }^{\mathrm{a}}$}

hanriot@pucminas.com.br

\section{José Ricardo Sodréd,}

ricardo.sodre@bcu.ac.uk

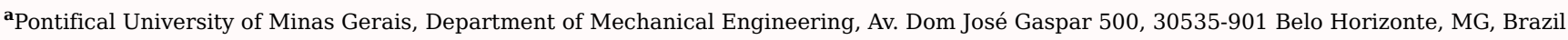

bAnhanguera Universitary Center, Av. Industrial, 3330, 09080-511 Santo André, SP, Brazil

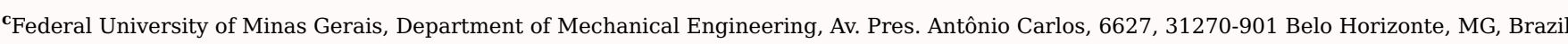

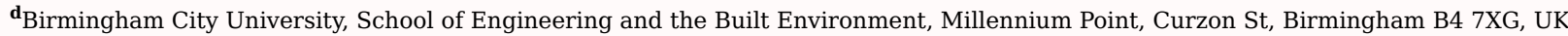

${ }^{*}$ Corresponding author.

\section{Abstract}

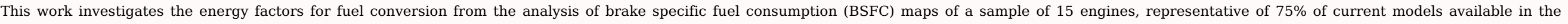

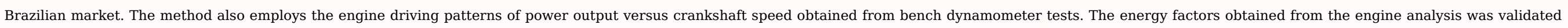

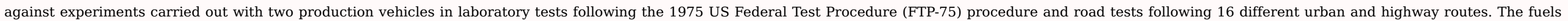

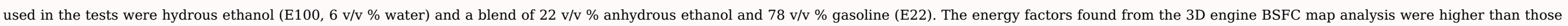

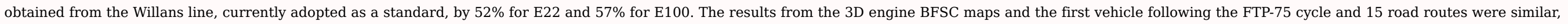
also close to the results from the second vehicle, qualifying them to be representative of modern flexible fuel spark ignition engines and vehicles.

Keywords: Ethanol; Energy factor; Specific fuel consumption; Willans line; Spark ignition engines

\section{Introduction}

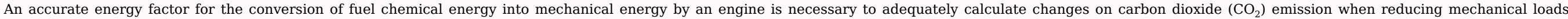

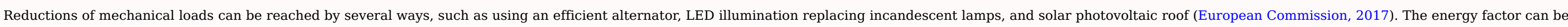

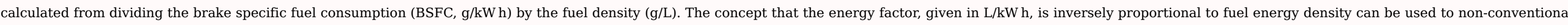

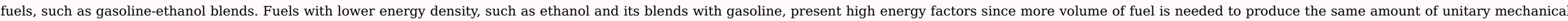
energy at the engine crankshaft. Therefore, fuel-dependent energy factors can be calculated by interpolating the respective heat values of the single fuels that composes the fuel blend. 


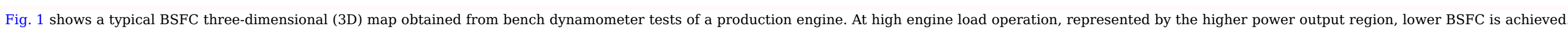

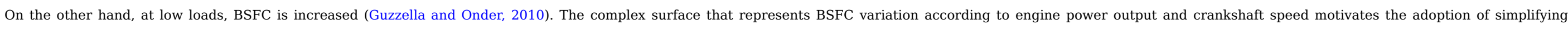

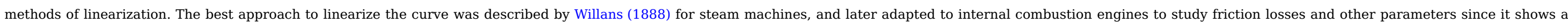
linear behavior for partial loads.

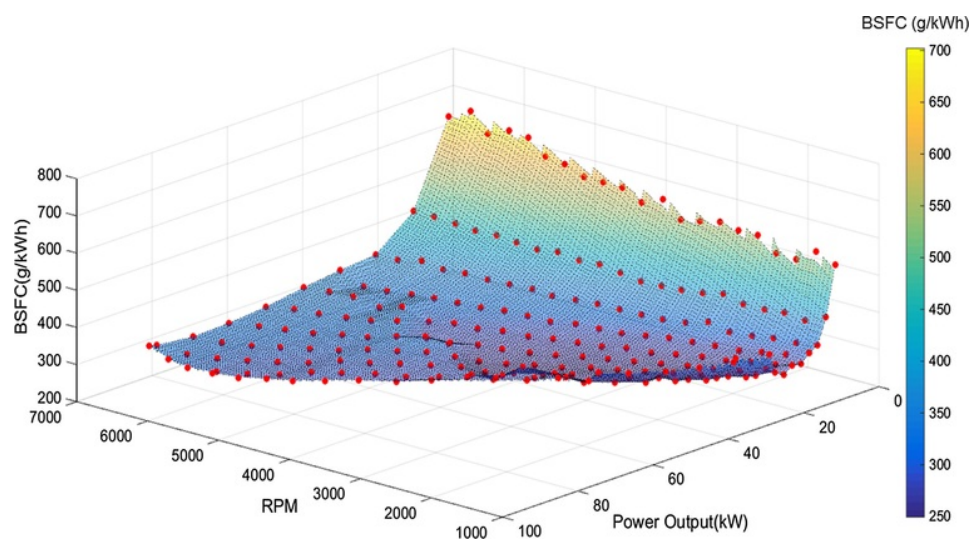

Fig. 1 Typical 3D BFSC map for a production engine.

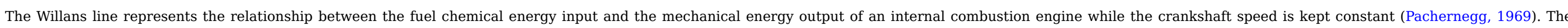

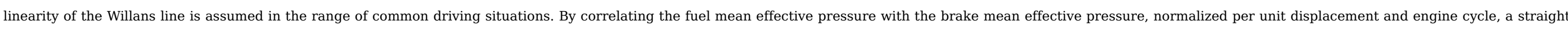

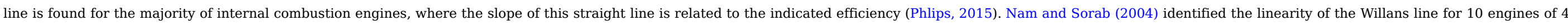

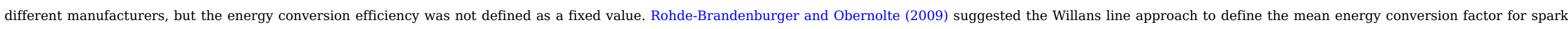

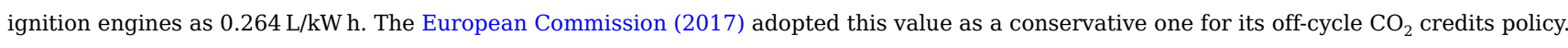

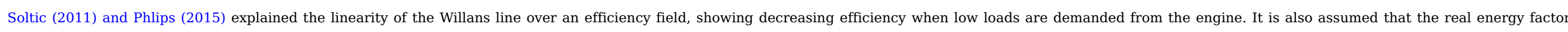

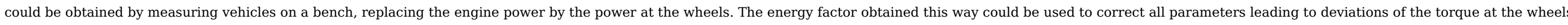

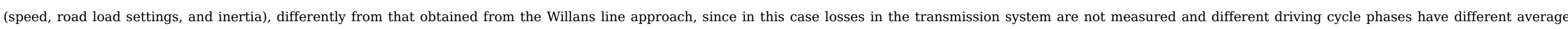

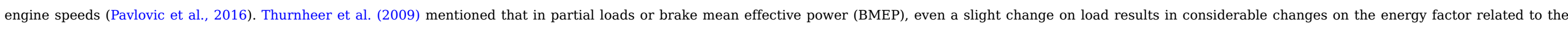
conversion of fuel energy into mechanical energy.

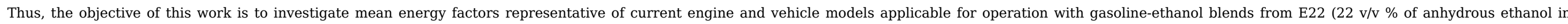

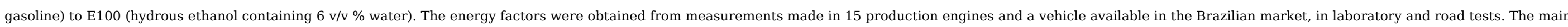

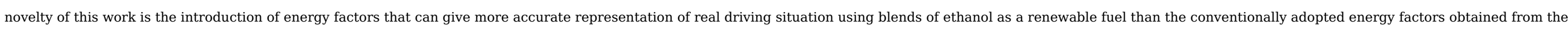
Willans line approach.

\section{Methodology}

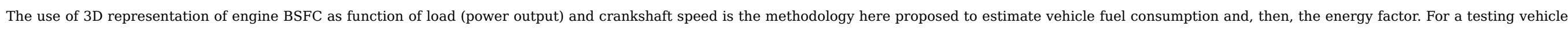

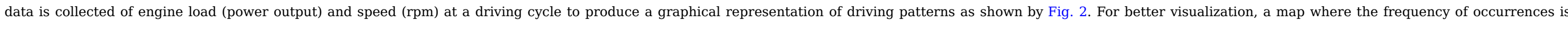

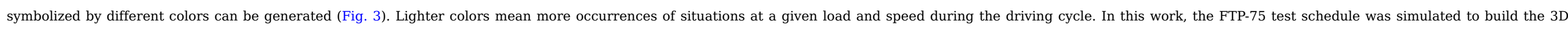
engine maps. 


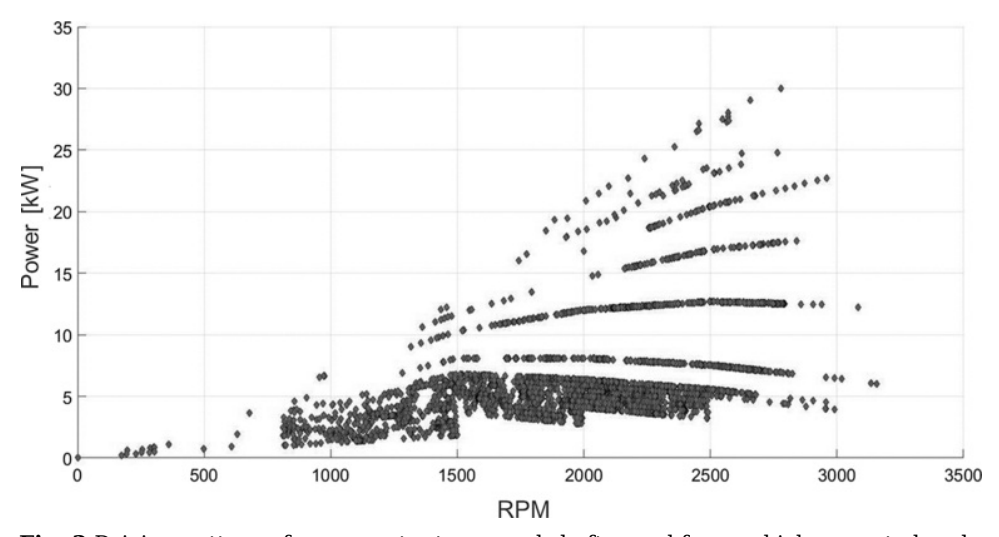

Fig. 2 Driving pattern of power output vs. crankshaft speed for a vehicle operated under the FTP-75 standard test schedule.

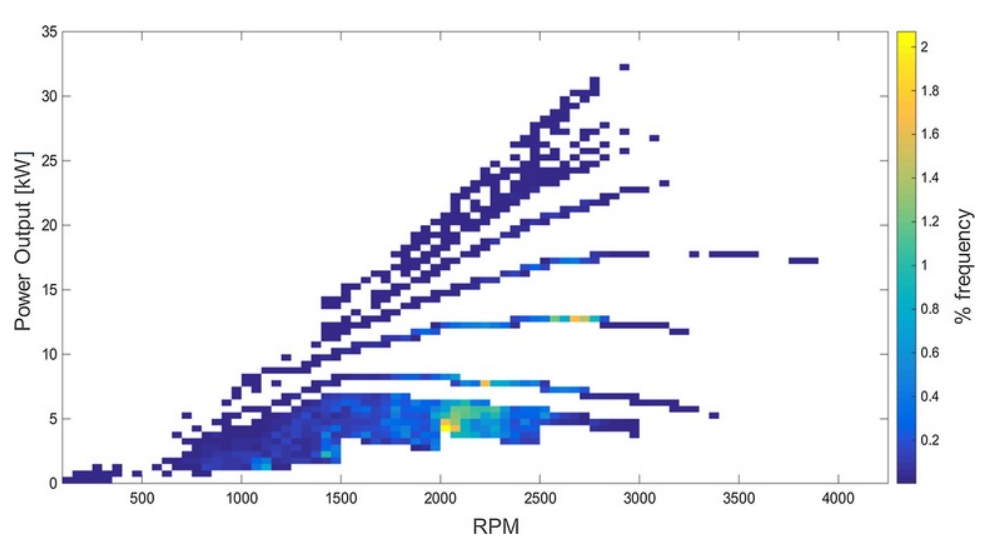

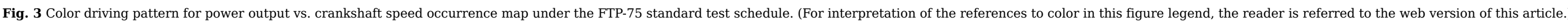

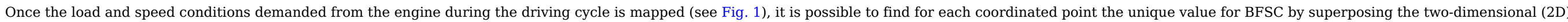

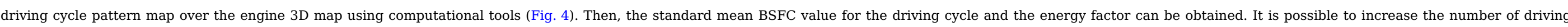

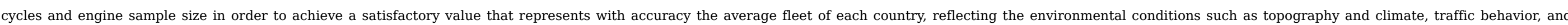
different vehicle and engine technologies operating with various fuels.

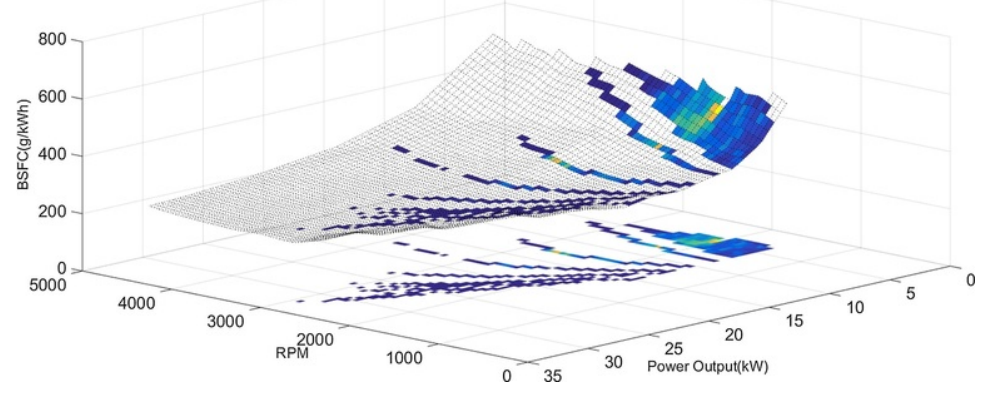

Fig. 4 Driving pattern intersection with 3D BFSC map 


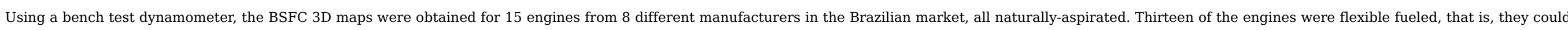

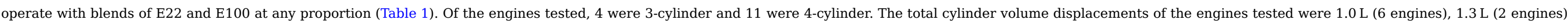

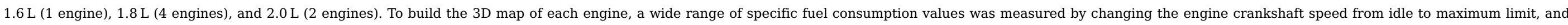
the power output from zero to rated value (Fig. 5). The engine BSFC 3D maps obtained were stored in a file containing all data necessary to calculate the energy factor as function of engine load and speed.

Table 1 Engines tested by manufacturer, displacement, number of cylinders, and fuel.

\begin{tabular}{|c|c|c|c|}
\hline Manufacturer & Displacement & Cylinders & Fuel \\
\hline \multirow[t]{2}{*}{ A } & $1.0 \mathrm{~L}$ & 3 & E22-E100 \\
\hline & $2.0 \mathrm{~L}$ & 4 & E22-E100 \\
\hline B & $1.8 \mathrm{~L}$ & 4 & E22-E100 \\
\hline C & $1.8 \mathrm{~L}$ & 4 & E22-E100 \\
\hline \multirow[t]{3}{*}{$\mathrm{D}$} & $1.0 \mathrm{~L}$ & 3 & E22-E100 \\
\hline & $1.8 \mathrm{~L}$ & 4 & E22 \\
\hline & $2.0 \mathrm{~L}$ & 4 & E22-E100 \\
\hline \multirow[t]{2}{*}{$\mathrm{E}$} & $1.0 \mathrm{~L}$ & 3 & E22-E100 \\
\hline & $1.0 \mathrm{~L}$ & 4 & E22-E100 \\
\hline \multirow[t]{2}{*}{$\mathrm{F}$} & $1.3 \mathrm{~L}$ & 4 & E22-E100 \\
\hline & $1.8 \mathrm{~L}$ & 4 & E22-E100 \\
\hline \multirow[t]{3}{*}{ G } & $1.0 \mathrm{~L}$ & 3 & E22-E100 \\
\hline & $1.0 \mathrm{~L}$ & 4 & E22-E100 \\
\hline & $1.6 \mathrm{~L}$ & 4 & E22-E100 \\
\hline $\mathrm{H}$ & $1.3 \mathrm{~L}$ & 4 & E22 \\
\hline
\end{tabular}

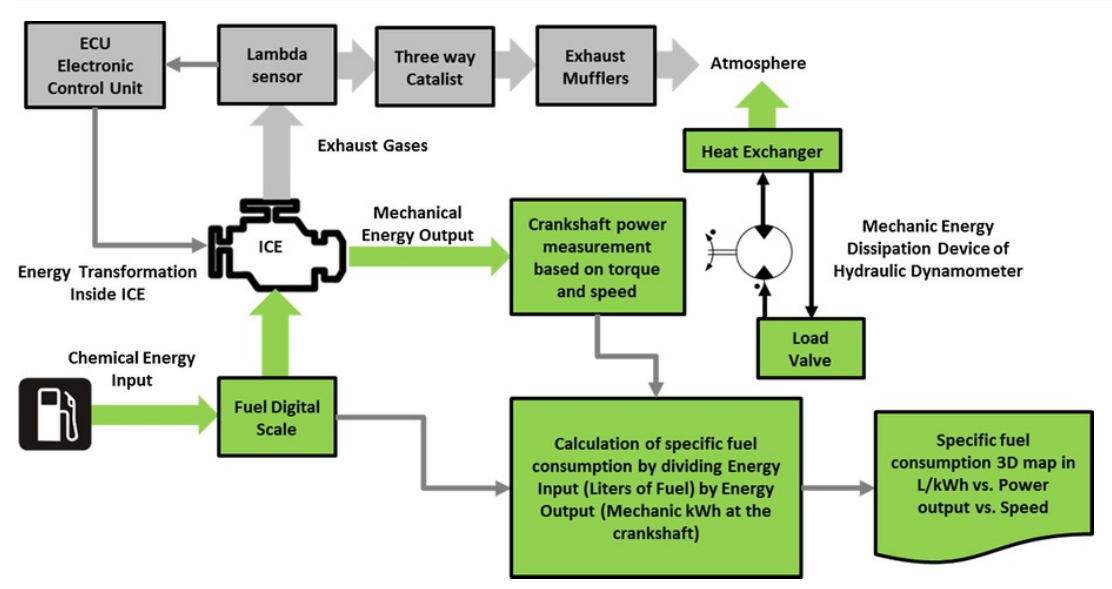

Fig. 5 Workflow used to obtain the specific fuel consumption 3D map. 


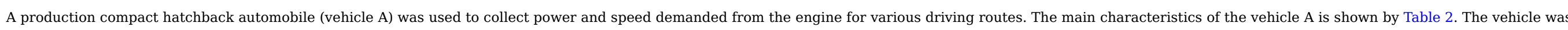

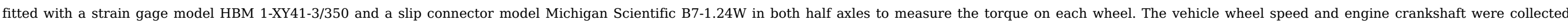

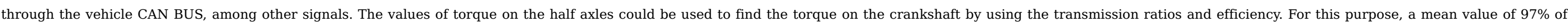
transmission efficiency was adopted based on information from the vehicle manufacturer.

Table 2 Vehicle characteristics.

\begin{tabular}{|c|c|c|}
\hline Parameter & Vehicle A & Vehicle B \\
\hline Energy consumption (MJ/km) & 1.55 & 1.43 \\
\hline Body & Hatchback 4 doors & Hatchback 4 doors \\
\hline Curb weight (kg) & 990 & 945 \\
\hline Passenger capacity & 5 & 5 \\
\hline Cylinder displacement $\left(\mathrm{cm}^{3}\right)$ & 1368 & 999 \\
\hline Engine type & Spark ignition & Spark ignition \\
\hline Bore $\times$ stroke $(\mathrm{mm})$ & $72 \times 84$ & $70 \times 86.5$ \\
\hline N. of cylinders & 4 & 3 \\
\hline Valves per cylinder & 2 & 2 \\
\hline Compression ratio & $12.35: 1$ & $13.2: 1$ \\
\hline Fuel & E22-E100 (flexible fuel) & E22-E100 (flexible fuel) \\
\hline Rated power $(\mathrm{kW})$ & $62.5 @ 5750$ rpm & $56.6 @ 6250$ rpm \\
\hline Rated torque $(\mathrm{N} \cdot \mathrm{m})$ & $122.6 @ 3500$ rpm & $106.9 @ 3250$ rpm \\
\hline Gearbox & Manual & Automated \\
\hline \multirow[t]{5}{*}{ Gear ratios } & $4.100: 1$ & $4.273: 1$ \\
\hline & $2.174: 1$ & $2.316: 1$ \\
\hline & 1.480:1 & $1.444: 1$ \\
\hline & 1.121:1 & 1.029:1 \\
\hline & 0.829:1 & $0.795: 1$ \\
\hline Differential/final ratio & $4.071: 1$ & 4.067:1 \\
\hline Length (mm) & 3811 & 3566 \\
\hline Width (mm) & 1636 & 1633 \\
\hline Height (mm) & 1480 & 1502 \\
\hline Tires & 175/65R14 & 175/65R14 \\
\hline
\end{tabular}

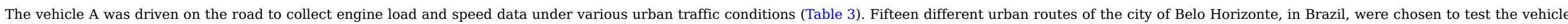

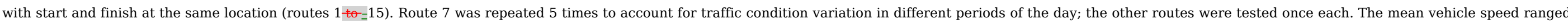

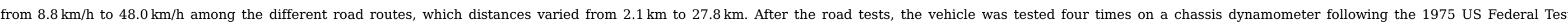




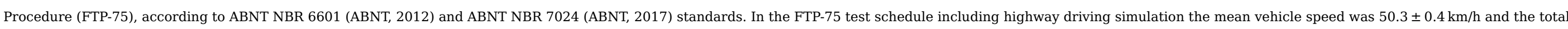

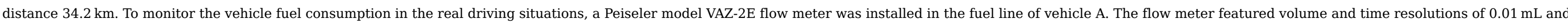
$1 \mathrm{~s}$.

Table 3 Characteristics of the driving cycles used.

\begin{tabular}{|c|c|c|c|c|c|}
\hline Route & Distance $(\mathrm{km})$ & Mean speed $(\mathrm{km} / \mathrm{h})$ & Vehicle & E22 energy conversion factor (L/kW h) & E100 energy conversion factor $(\mathrm{L} / \mathrm{kW} \mathrm{h})$ \\
\hline 1 & 18.8 & 27.5 & A & 0.44 & 0.63 \\
\hline 2 & 9.4 & 17.2 & A & 0.44 & 0.62 \\
\hline 3 & 17.7 & 35.5 & A & 0.42 & 0.61 \\
\hline 4 & 18.6 & 47.2 & A & 0.41 & 0.59 \\
\hline 5 & 19.1 & 32.8 & A & 0.45 & 0.63 \\
\hline 6 & 12.0 & 8.7 & A & 0.46 & 0.66 \\
\hline 7 & 27.8 & 30.3 & A & 0.43 & 0.63 \\
\hline 8 & 30.7 & 48.0 & A & 0.42 & 0.61 \\
\hline 9 & 24.7 & 35.3 & A & 0.44 & 0.62 \\
\hline 10 & 2.1 & 18.6 & A & 0.45 & 0.66 \\
\hline 11 & 21.1 & 42.8 & A & 0.42 & 0.61 \\
\hline 12 & 6.3 & 19.9 & A & 0.42 & 0.61 \\
\hline 13 & 24.2 & 26.7 & A & 0.43 & 0.63 \\
\hline 14 & 3.1 & 19.2 & A & 0.46 & 0.67 \\
\hline 15 & 27.5 & 22.8 & A & 0.44 & 0.64 \\
\hline Average & - & - & - & 0.44 & 0.63 \\
\hline 16 & 84.6 & 32.0 & B & 0.48 & 0.65 \\
\hline FTP-75 & 34.2 & 50.3 & A & 0.43 & 0.63 \\
\hline
\end{tabular}

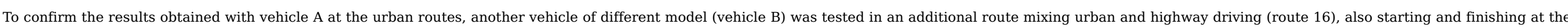

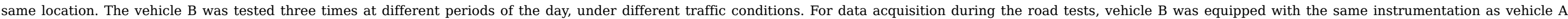
Vehicle B characteristics are shown by Table 2, and the mixed route R16 distance and average speed is shown by Table 3.

\section{Results and Đdiscussion}

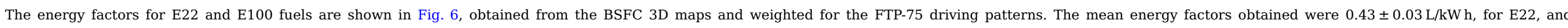

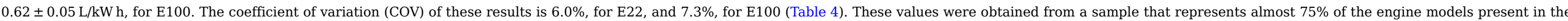

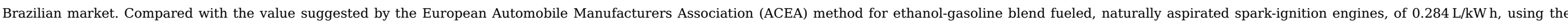

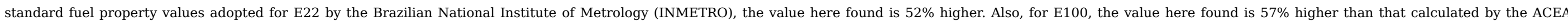
method for ethanol-gasoline blend fuels with standard energy and density values adopted by INMETRO, of 0.396 L/kW h. 


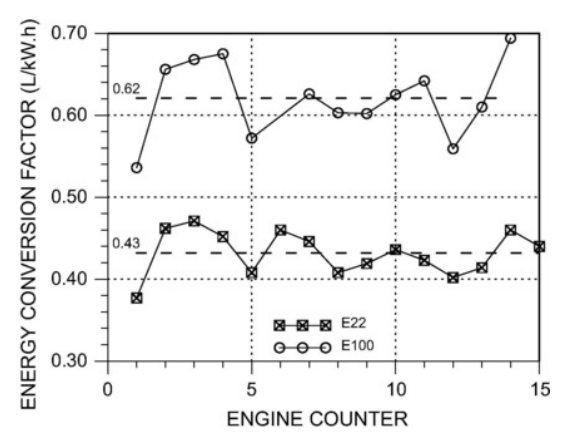

Fig. 6 Specific mean energy conversion factor obtained from graphical evaluation of BSFC map for 15 engine models operated under the FTP-75 cycle.

Table 4 Statistical data of the results from the engine tests: mean value, standard deviation and coefficient of variation (COV).

\begin{tabular}{|c|c|c|c|c|c|c|c|}
\hline Manufacturer & Displacement & Cylinders & Fuel Type Engine & $\begin{array}{c}\text { E22 } \\
\text { g/kW h }\end{array}$ & $\begin{array}{c}\text { E22 } \\
\text { L/kW h }\end{array}$ & $\begin{array}{l}\text { E100 } \\
\text { g/kW h }\end{array}$ & $\begin{array}{l}\text { E100 } \\
\text { L/kW h }\end{array}$ \\
\hline \multirow[t]{2}{*}{ A } & $1.0 \mathrm{~L}$ & 3 & E22-E100 & 0.28 & 0.38 & 0.43 & 0.54 \\
\hline & $2.0 \mathrm{~L}$ & 4 & E22-E100 & 0.34 & 0.46 & 0.53 & 0.66 \\
\hline B & $1.8 \mathrm{~L}$ & 4 & E22-E100 & 0.35 & 0.47 & 0.54 & 0.67 \\
\hline $\mathrm{C}$ & $1.8 \mathrm{~L}$ & 4 & E22-E100 & 0.34 & 0.45 & 0.55 & 0.67 \\
\hline \multirow[t]{3}{*}{$\mathrm{D}$} & $1.0 \mathrm{~L}$ & 3 & E22-E100 & 0.30 & 0.41 & 0.46 & 0.57 \\
\hline & $1.8 \mathrm{~L}$ & 4 & E22 & 0.34 & 0.46 & & \\
\hline & $2.0 \mathrm{~L}$ & 4 & E22-E100 & 0.33 & 0.45 & 0.51 & 0.63 \\
\hline \multirow[t]{2}{*}{$\mathrm{E}$} & $1.0 \mathrm{~L}$ & 3 & E22-E100 & 0.30 & 0.41 & 0.49 & 0.60 \\
\hline & $1.0 \mathrm{~L}$ & 4 & E22-E100 & 0.31 & 0.42 & 0.49 & 0.60 \\
\hline \multirow[t]{2}{*}{$\mathrm{F}$} & $1.3 \mathrm{~L}$ & 4 & E22-E100 & 0.32 & 0.44 & 0.51 & 0.62 \\
\hline & $1.8 \mathrm{~L}$ & 4 & E22-E100 & 0.32 & 0.42 & 0.52 & 0.64 \\
\hline \multirow[t]{3}{*}{ G } & $1.0 \mathrm{~L}$ & 3 & E22-E100 & 0.30 & 0.40 & 0.45 & 0.56 \\
\hline & $1.0 \mathrm{~L}$ & 4 & E22-E100 & 0.31 & 0.41 & 0.49 & 0.61 \\
\hline & $1.6 \mathrm{~L}$ & 4 & E22-E100 & 0.34 & 0.46 & 0.56 & 0.69 \\
\hline \multirow[t]{4}{*}{$\mathrm{H}$} & $1.3 \mathrm{~L}$ & 4 & E22 & 0.33 & 0.44 & & \\
\hline & & Mean & & 0.32 & 0.43 & 0.50 & 0.62 \\
\hline & & Standard deviation & & 0.02 & 0.03 & 0.04 & 0.05 \\
\hline & & COV (\%) & & & $6.0 \%$ & & $7.3 \%$ \\
\hline
\end{tabular}

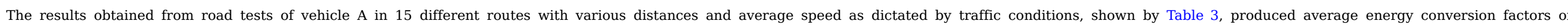

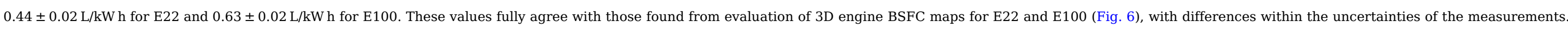

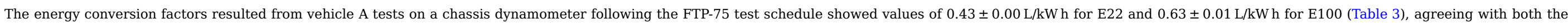




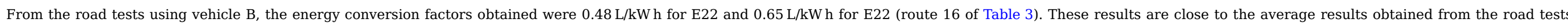

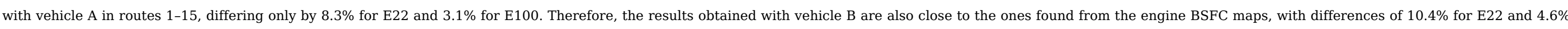

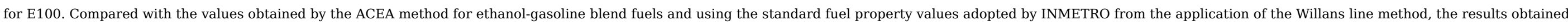

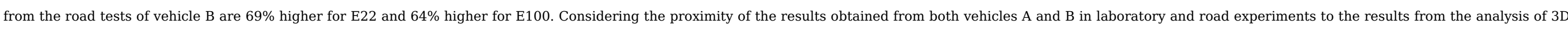
BSFC maps, it can be affirmed that the proposed method is a reliable one to calculate energy conversion factors of current flexible fuel engines.

\section{Conclusions}

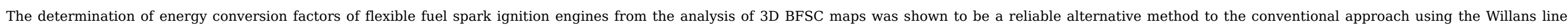

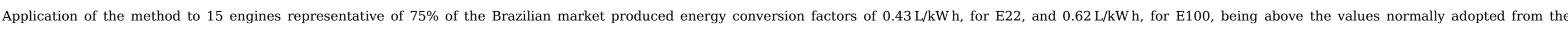

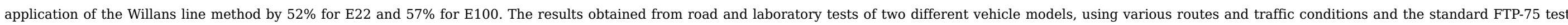

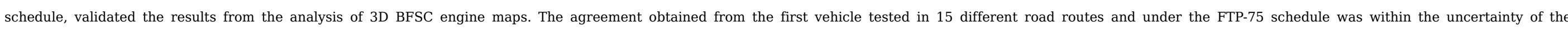

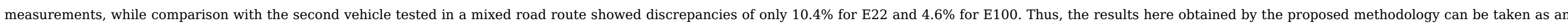
updated representation of energy conversion factors of modern flexible fuel spark ignition engines, applicable for operation with both gasoline and ethanol.

\section{Acknowledgments}

The authors thank the Brazilian Ministry of Development, Industry and Foreign Trade, CAPES, CNPq, FAPEMIG, and FCA Latam for the financial support to this project.

\section{References}

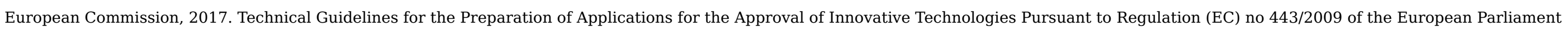
and of the Council. Brussels.

Guzzella L. and Onder C., Introduction to Modeling and Control of Internal Combustion Engines System, 2010, Springer Verlag Berlin Heidelberg; Berlin.

Nam, E.K., Sorab, J., 2004. Friction Reduction Trends in Modern Engines. SAE Technical Paper 2004-01-1456.

Pachernegg, S.J., 1969. A Closer Look at the Willans-Line. SAE Technical Paper 690182.

Pavlovic J., Marotta A. and Ciuffo B., $\mathrm{CO}_{2}$ emissions and energy demands of vehicles tested under the NEDC and the new WLTP type approval test procedures, Appl. Energy 177, 2016, 661-670.

Phlips P., Analytic engine and transmission models for vehicle fuel consumption estimation, SAE Int. J. Fuels Lubr. 8 (2), 2015, 423-440.

Rohde-Brandenburger K. and Obernolte J., $\mathrm{CO}_{2}$ potential of lightweight designed cars, Materialprufung 51 (1-2), 2009, 55-63.

Soltic, P., 2011. CO2 Reduction and Cost Efficiency Potential of Natural Gas Hybrid Passenger Cars. SAE Technical Paper 2011-24-0110.

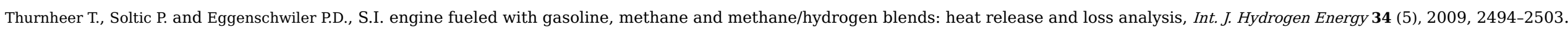

Willans P.W., Economy trials of a non-condensing steam engine: simple, compound and triple, Min. Proc. Inst. Civil Eng. 93, 1888, 128-188.

\section{Graphical abstract}




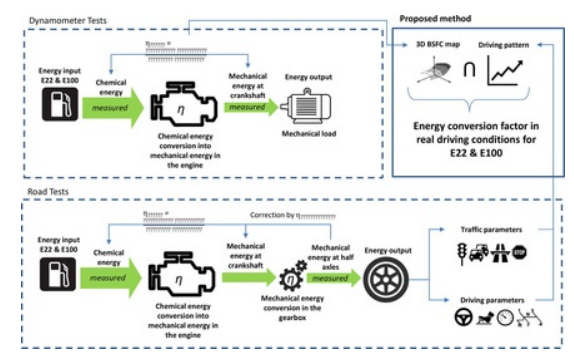

Highlights

- Energy factors were obtained for gasoline and ethanol fueled engines and vehicles.

- Use of 3D engine BFSC maps produced consistent results for flexible fuel engines.

- Energy conversion factor for E22 was $0.43 \mathrm{~L} / \mathrm{kW} \mathrm{h}$, from laboratory and road tests.

- Energy conversion factor for E100 was $0.62 \mathrm{~L} / \mathrm{kW}$, from laboratory and road tests.

\section{Queries and Answers}

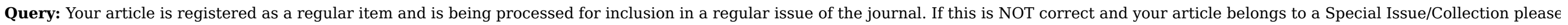
contact a.begum@elsevier.com immediately prior to returning your corrections.

Answer: I confirm the article should be registered as a regular item.

Query: The author names have been tagged as given names and surnames (surnames are highlighted in teal color). Please confirm if they have been identified correctly. Answer: The surname of Sergio de Morais Hanriot is just Hanriot. The surnames of the remaining authors have correctly been identified.

Query: Please note that figures were not sequentially cited in the text, and have been renumbered in the text. Please check, and correct if necessary.

Answer: The figures are now correctly cited in the text.

Query: Have we correctly interpreted the following funding source(s) and country names you cited in your article: FAPEMIG, Brazil; CAPES, Brazil; CNPq, Brazil? /

Answer: Yes 